\title{
BMJ Open Effectiveness of virtual and augmented reality for improving knowledge and skills in medical students: protocol for a systematic review
}

\author{
Zain Hussain (D) , ${ }^{1,2}$ Dominic Mark Ng, ${ }^{3}$ Nouf Alnafisee, ${ }^{3}$ Zakariya Sheikh (D) , ${ }^{2}$ \\ Nathan Ng (D) , ${ }^{2}$ Ateeb Khan, ${ }^{4}$ Amir Hussain (D) , ${ }^{5}$ Debbie Aitken, ${ }^{2,6}$ Aziz Sheikh (1) ${ }^{7}$
}

To cite: Hussain Z, Ng DM, Alnafisee $\mathrm{N}$, et al. Effectiveness of virtual and augmented reality for improving knowledge and skills in medical students: protocol for a systematic review. BMJ Open 2021;11:e047004. doi:10.1136/ bmjopen-2020-047004

- Prepublication history and additional supplemental material for this paper are available online. To view these files, please visit the journal online (http://dx.doi.org/10.1136/ bmjopen-2020-047004).

ZH and DMN are joint first authors.

AH, DA and AS are joint senior authors.

Received 20 November 2020 Accepted 07 June 2021

Check for updates

(c) Author(s) (or their employer(s)) 2021. Re-use permitted under CC BY-NC. No commercial re-use. See rights and permissions. Published by BMJ.

For numbered affiliations see end of article.

Correspondence to

Dr Zain Hussain;

zhuss95@gmail.com

\section{ABSTRACT}

Introduction Virtual reality (VR) and augmented reality (AR) technologies are increasingly being used in undergraduate medical education. We aim to evaluate the effectiveness of VR and AR technologies for improving knowledge and skills in medical students.

Methods and analysis Using Best Evidence in Medical Education (BEME) collaboration guidelines, we will search MEDLINE (via PubMed), Education Resources Information Center, PsycINFO, Web of Knowledge, Embase and the Cochrane Central Register of Controlled Trials for Englishlanguage records, from January 1990 to March 2021. Randomised trials that studied the use of VR or AR devices for teaching medical students will be included. Studies that assessed other healthcare professionals, or did not have a comparator group, will be excluded. The primary outcome measures relate to medical students' knowledge and clinical skills. Two reviewers will independently screen studies and assess eligibility based on our prespecified eligibility criteria, and then extract data from each eligible study using a modified BEME coding form. Any disagreements will be resolved by discussion or, if necessary, the involvement of a third reviewer. The BEME Quality Indicators checklist and the Cochrane Risk of Bias Tool will be used to assess the quality of the body of evidence. Where data are of sufficient homogeneity, a meta-analysis using a random-effects model will be conducted. Otherwise, a narrative synthesis approach will be taken and studies will be evaluated based on Kirkpatrick's levels of educational outcomes and the Synthesis Without Meta-analysis guidelines.

Ethics and dissemination Ethical approval is not required for this systematic review as no primary data are being collected. We will disseminate the findings of this review through scientific conferences and through publication in a peer-reviewed journal.

\section{INTRODUCTION}

The acquisition of clinical and examination skills is a vital component of medical education. ${ }^{1}$ Traditionally, the acquisition of such skills has been via mentorship models from senior clinicians in clinical environments. However, due to increased clinical loads and reduced working hours, it is often difficult for
Strengths and limitations of this study

- First systematic review assessing the effectiveness of virtual reality and augmented reality technologies for improving knowledge and skills outcomes in medical students

- A rigorous search strategy will be employed, which will involve searching multiple databases, grey literature and for non-indexed trials.

- The quality of evidence will be assessed using the Best Evidence in Medical Education Quality Indicators checklist and the Cochrane Risk of Bias Tool.

- Limitations include the likely heterogeneity of interventions and outcomes investigated.

trainees to have the same exposure to practical skills as their predecessors. ${ }^{2}$ Furthermore, due to increasing infection control risks and costs associated with training practical skills, the need to develop alternative teaching environments is pressing. ${ }^{34}$ One solution is the use of immersive technologies for education, which place students in a virtual environment whereby they can perform practical procedures as well as interact with a variety of simulated clinical scenarios. This can be useful in the development of physical examination skills (through using sound, tactile and visual examination findings), development of basic life support skills, surgical training and human anatomy. ${ }^{5-7}$ Some advantages of such technologies include that they allow for spaced repetition, reduce time burden on senior clinicians and permit students to practice in their own time. The use of simulators also provide real-time feedback, and record data from different attempts, to compare to those of different levels of expertise. ${ }^{8}$

In medical education, the three main types of technology used to construct these simulated environments are: virtual reality 


\begin{tabular}{|c|c|}
\hline $\begin{array}{l}\text { Term (as } \\
\text { defined by } \\
\text { Moro et } \mathrm{al}^{9} \text { ) }\end{array}$ & Abbreviation \\
\hline $\begin{array}{l}\text { Undergraduate } \\
\text { medical } \\
\text { education }\end{array}$ & $\begin{array}{l}\text { Medical students are described as any } \\
\text { student undertaking a course of study } \\
\text { at a medical school to reach a primary } \\
\text { qualification in medicine, enabling them to } \\
\text { practice as doctors }\end{array}$ \\
\hline $\begin{array}{l}\text { Virtual Reality } \\
\text { (VR) }\end{array}$ & $\begin{array}{l}\text { Immersion of a user in a synthetic } \\
\text { environment, experienced through their } \\
\text { senses (sight, hearing and motion), } \\
\text { which mimics properties of the real world } \\
\text { through head mounted displays, stereo } \\
\text { headphones and motion tracking systems. }\end{array}$ \\
\hline $\begin{array}{l}\text { Augmented } \\
\text { Reality (AR) }\end{array}$ & $\begin{array}{l}\text { Superimposition of digital models on to the } \\
\text { real world, using a camera and a screen } \\
\text { (eg, smartphone or tablet). Users can then } \\
\text { interact with the virtual and real-world } \\
\text { elements of their environment. }\end{array}$ \\
\hline $\begin{array}{l}\text { Mixed Reality } \\
\text { (MR) }\end{array}$ & $\begin{array}{l}\text { A significant advancement of AR, whereby } \\
\text { virtual objects can be mapped onto the } \\
\text { real world. MR headset devices present } \\
\text { holographic renderings of images in their } \\
\text { display, which can be interacted with. }\end{array}$ \\
\hline
\end{tabular}

$A R$, augmented reality; MR, mixed reality; VR, virtual reality.

(VR), augmented reality (AR) and mixed reality (MR) (as defined by Moro et $a l^{9}$ in table 1). VR is in essence a method that 'provides a three-dimensional (3D) and dynamic view of structures and the ability of the user to interact with them' via a digital interface. ${ }^{10} \mathrm{AR}$ is a composite view produced by the superimposing of a computer generated image over a user's view on the real world (eg, using your phone to project an image onto a table). MR is an advancement of AR in that it is multisensory and generally involves the use of a computer headset, earphones and tactile gloves to enhance sensory feedback from the clinical scenario and make it as realistic as possible; however, unlike VR it does not take place within a wholly virtual environment, with certain aspects (ie, the background) still remaining 'real'.

\section{E-Learning and current literature}

The use of e-learning in medical education has been explored to varying degrees in the literature. A recent review exploring the barriers and solutions to online learning in medical education identified the need for institutional support and a clear strategy on how e-tools and programmes should be applied, as their application was often undirected and unsuccessful. ${ }^{8}$ They also identified the necessity of interfaculty collaboration to create a cohesive e-learning system. Further barriers to successful e-learning included poor technical skills, educational skills and training, which could be addressed by improving the training of educators in computational literacy. ${ }^{11}$ Immersive technologies, which constitute one modality of e-learning, are being increasingly used to improve knowledge and skills outcomes. Further research into their role and effectiveness would build the required evidence base for industry and medical education bodies to enhance the development and uptake of e-learning.

There have been a number of reviews exploring the use of VR tools for healthcare professionals in different stages of their training, and the vast majority have called for further research in the area. The reviews have primarily focused on healthcare professionals acquiring specific surgical skills (eg, laparoscopy, ear, nose and throat (ENT), ophthalmology) or learning a particular clinical procedure. ${ }^{12-14}$ A recent comprehensive review evaluated the effectiveness of VR in educating health professionals, and found it to improve knowledge and skills outcomes. However, it focused on all healthcare professionals, and therefore, may have included clinical skills which are not relevant for medical students. ${ }^{15}$ While the review attempted to extract outcome measures relating to postintervention knowledge, skills, attitudes, satisfaction and change in behaviour, almost all of the included studies captured either knowledge or skills outcomes. Although extensive, the review only searched for articles up to 2017 , since which there have been several studies published. ${ }^{5916-21}$ Furthermore, it did not describe the types of intervention used and only included information on their effectiveness. A Cochrane systematic review in $2015^{18}$ aimed to explore the evidence base for introducing VR into ENT training programmes. The studies assessed the technical skills of both surgical trainees and medical students in controlled environments, for either endoscopic sinus or temporal bone surgery. Nine studies were analysed, of which four included medical students. These studies suggested that VR simulation could be a useful supplementary learning tool for medical students, showing improved anatomical identification scores (MD 4.3, $95 \%$ CI 2.31 to 6.29 ) after use of VR simulators. A systematic review by Tang $e t a l^{22}$ investigated the current state and role of AR technologies in medical education. It showed current uses for AR include surgical training, anatomy teaching and as a component of the blended learning approach. Crucially, however, it identified the lack of a review which explores the effectiveness of AR technologies in medical education, and of a standardised assessment tool.

Given the current state of the literature and the burgeoning interest in using immersive technologies to teach medical students, a review is warranted to provide educators as well as researchers with a better understanding of the uses of these tools as documented in the literature, and with information on their effectiveness compared with standard practice. As such, this review aims to evaluate the effectiveness of VR and AR technologies for improving postintervention knowledge and skills outcomes in medical students. It will also describe the characteristics and objectives of the identified devices, as indicated in the literature. Our findings will inform 
medical schools and educational bodies on the current state and effectiveness of immersive technologies in undergraduate medical education and will help shape the design of future curricula.

\section{METHODS AND ANALYSIS}

The Preferred Reporting Items for Systematic Reviews and Meta-Analyses (PRISMA) Protocols guidelines were used to facilitate development of this protocol, see online supplemental appendix 1. We will use the Best Evidence in Medical Education (BEME) collaboration guidelines to conduct our systematic review to answer the following research questions:

1. Are VR technologies effective at improving knowledge and skills outcomes in medical students?

2. Are AR technologies effective at improving knowledge and skills outcomes in medical students?

BEME guidelines were chosen as the systematic review framework due to their specificity to medical education methodology. Any significant amendments made to our protocol will be documented and published with the results of our systematic review. Reporting of the review will be informed by the PRISMA guidance and the Synthesis Without Meta-analysis guidelines. ${ }^{23}$

The review has been submitted to and is awaiting registration on the International Prospective Register of Systematic Reviews (ID 250531).

\section{Inclusion criteria}

The inclusion and exclusion criteria are summarised in table 2.

\section{Population}

Only studies including medical students in undergraduate medical education will be included in this review; those focused only on medical professionals or postgraduate learners will be excluded. Studies with both undergraduate and postgraduate learners will be included if data relating to undergraduate students can be separately analysed.

\section{Intervention}

Due to the varied nature of VR simulators and the environment being simulated, it is difficult to define what constitutes immersive (VR, AR and MR) technologies. However, we have provided our definitions of these (table 1), and will include all VR/AR delivery devices and levels of immersion. In order to include all relevant studies, all spatially immersive visualisation technologies which simulate an interactive 3D environment will be included, whether or not they include tactile feedback or other sensory feedback.

\section{Study design and comparators}

Randomised trials which provide primary data for our outcomes will be included. We will evaluate and interpret data and results carefully in the context of their design and will assess and report the quality of each study type.
Table 2 Inclusion and exclusion criteria for the proposed study based on a PICO format

\begin{tabular}{|c|c|c|}
\hline & Inclusion criteria & Exclusion criteria \\
\hline Population & $\begin{array}{l}\text { Medical students } \\
\text { Undergraduate } \\
\text { medical education }\end{array}$ & $\begin{array}{l}\text { Only includes } \\
\text { healthcare } \\
\text { professionals or } \\
\text { postgraduate } \\
\text { learners (ie, no } \\
\text { medical students) }\end{array}$ \\
\hline Intervention & $\begin{array}{l}\text { VR, AR and MR } \\
\text { technologies }\end{array}$ & $\begin{array}{l}\text { Interventions not } \\
\text { explicitly using } \\
\text { VR, AR or MR } \\
\text { technologies }\end{array}$ \\
\hline Comparator & $\begin{array}{l}\text { Traditional or } \\
\text { alternative teaching } \\
\text { methods or } \\
\text { techniques (any } \\
\text { teaching method not } \\
\text { using the same VR/ } \\
\text { AR), where possible. }\end{array}$ & \\
\hline Outcomes & $\begin{array}{l}\text { Medical students' } \\
\text { knowledge (pre-test } \\
\text { and post-test scores). } \\
\text { Medical students' } \\
\text { skills }\end{array}$ & \\
\hline Study type & Randomised trials & $\begin{array}{l}\text { Non-randomised } \\
\text { trials } \\
\text { Qualitative studies } \\
\text { Systematic reviews } \\
\text { Meta-analyses } \\
\text { Letters to the editor } \\
\text { Case studies } \\
\text { Studies without a } \\
\text { comparator group } \\
\text { Uncontrolled } \\
\text { before-and-after } \\
\text { studies }\end{array}$ \\
\hline
\end{tabular}

AR, augmented reality; MR, mixed-reality; VR, virtual reality.

We will compare primary outcomes against traditional teaching methods or techniques (which do not use VR/ $\mathrm{AR})$.

\section{Outcome measures}

As there is significant heterogeneity in the tasks conducted in VR/AR environments as well as the type of VR/AR used, outlining one specific outcome measure to be extracted is not achievable. ${ }^{24}$ Instead, primary outcome measures relating to medical students' knowledge and skills will be extracted.

Knowledge will be defined as students' factual or conceptual understanding, and measured using any validated or non-validated instrument to obtain pretest and post-test scores. In the case of multiple post-test results, the difference between the pretest and first post-test will be calculated to include in our analysis.

Skills will be defined as students' ability to demonstrate a technique or procedure, and measured using validated 
or non-validated instruments (eg, to obtain pretest and post-test scores, task performance/errors, observed assessment scores).

\section{Search strategy and sources}

We will identify studies by searching the following electronic databases: MEDLINE (via PubMed), Education Resources Information Center, PsycINFO, Web of Knowledge, Embase and the Cochrane Central Register of Controlled Trials.

Databases will be searched for English-language records, from January 1990 to March 2021. Prior to 1990, the use of digital technologies was limited to basic tasks. Additional relevant studies will be identified based on expert knowledge of the reviewers. Grey literature will be identified by emailing primary authors of included studies and searching conference abstracts from relevant meetings.

We will develop our search strategy using a combination of Medical Subject Headings and keywords related to the following concepts: VR, AR and undergraduate medical education (medical school/medical students). A full electronic search strategy for PubMed is included in online supplemental appendix 2.

\section{Patient and public involvement}

No patient involved.

\section{Data collection}

Two reviewers (NA and NN) will identify studies which fit our inclusion/exclusion criteria independently using titles and abstracts. If there is any disagreement, then a discussion will take place between the two reviewers using the full text of the article in question. If there is still disagreement, then a third reviewer (AK) will be consulted. Cohen's kappa, a measure that identifies the level of agreement between our reviewers, will be calculated as well. ${ }^{25}$ A web-based app called Rayyan will be used to track studies that have been identified. ${ }^{26}$

As per PRISMA guidelines, a flow chart will be created once this has been completed to identify the number of studies found using our search terms, the final number of studies and the reason for exclusion of studies not included. $^{27}$

\section{Data extraction and management}

All data extraction from relevant studies will be carried out by two independent reviewers (NA and NN), using a modified version of the BEME coding form which will also include data on several measures, as seen in table 3 . Both authors will go through a process of orientation to the tool, before full extraction, to ensure inter-rater reliability to a kappa of at least 0.80 agreement. If needed, a third reviewer will be consulted to resolve disagreements (AK).

\section{Quality assessment}

Two independent reviewers (NN and NA) will conduct a risk of bias assessment, and similar to our study selection,
Table 3 Types of data that will be extracted

\begin{tabular}{|c|c|}
\hline Study & $\begin{array}{l}\text { Authors } \\
\text { Date of publication } \\
\text { Study design } \\
\text { Characteristics of control } \\
\text { Country } \\
\text { Funding }\end{array}$ \\
\hline Population & $\begin{array}{l}\text { Sample size of both arms } \\
\text { Sex proportion } \\
\text { Mean age }\end{array}$ \\
\hline Intervention & $\begin{array}{l}\text { Type of VR, AR or MR device used, including } \\
\text { platform. } \\
\text { Type of teaching method or technique } \\
\text { Characteristics of control method/technique } \\
\text { 3-DOF or 6-Degrees of Freedom (DoF) VR } \\
\text { simulator } \\
\text { Interactive or not interactive } \\
\text { Duration of the session } \\
\text { No of sessions } \\
\text { Task given or skill being developed }\end{array}$ \\
\hline $\begin{array}{l}\text { Outcome } \\
\text { measures }\end{array}$ & $\begin{array}{l}\text { Students' knowledge postintervention } \\
\text { Students' skills postintervention }\end{array}$ \\
\hline
\end{tabular}

AR, augmented reality; MR, mixed-reality; VR, virtual reality.

if there are any points of disagreement which cannot be resolved then a third reviewer (DMN) will be consulted. We will conduct a formal risk of bias assessment for randomised trials using The Cochrane Risk of Bias Tool. ${ }^{28}$ The BEME Quality indicators checklist, developed by Buckley et $a l^{29}$ will be used to evaluate internal validity. The checklist consists of 11 criteria, listed in table 4, which are designed specifically for studies in medical education as per the recommendations of the BEME collaboration. Each criterion can be listed as 'met, 'unmet' or 'unclear' and a study is required to meet a minimum of seven indicators in order to be deemed high quality.

\section{Synthesis of extracted evidence}

First, we will describe all studies that met the inclusion criteria, based on the information extracted using table 3 . Information on the type of VR or AR device used, their characteristics, and on the task given or skill being developed (eg, basic scientific knowledge or clinical skill), will provide insights into the role/use of each of the VR or AR technologies being used.

We will take an iterative and responsive approach as we proceed through data extraction and evaluate studies. Where we find sufficient homogeneity to combine, we will follow standard methods for meta-analysis in the Cochrane Handbook, using the random-effects model. ${ }^{28}$ In the case of heterogeneous data, we will conduct a comprehensive narrative synthesis of the evidence, and will group and report studies according to a modification of Kirkpatrick's levels of educational outcomes (hierarchy) ${ }^{30}$ Narrative synthesis is often criticised for the lack of transparency in the methods used; to aid transparency, 
Table 4 BEME quality indicators checklist specific to studies in medical education

\section{Questions}

\begin{tabular}{|c|c|}
\hline $\begin{array}{l}\text { Research } \\
\text { question }\end{array}$ & $\begin{array}{l}\text { Is the research question or hypothesis } \\
\text { clearly stated? }\end{array}$ \\
\hline Study subjects & $\begin{array}{l}\text { Is the subject group appropriate for the } \\
\text { study being carried out? }\end{array}$ \\
\hline $\begin{array}{l}\text { Data collection } \\
\text { methods }\end{array}$ & $\begin{array}{l}\text { Are the methods used appropriate for the } \\
\text { research question and context? }\end{array}$ \\
\hline $\begin{array}{l}\text { Completeness of } \\
\text { data }\end{array}$ & $\begin{array}{l}\text { Attrition rates/acceptable questionnaire } \\
\text { response rates }\end{array}$ \\
\hline $\begin{array}{l}\text { Risk of bias } \\
\text { assessment }\end{array}$ & $\begin{array}{l}\text { Is a statement of author positionality and } \\
\text { a risk of bias assessment included? }\end{array}$ \\
\hline Analysis of results & $\begin{array}{l}\text { Are the statistical and other methods of } \\
\text { results analysis used appropriate? }\end{array}$ \\
\hline Conclusions & $\begin{array}{l}\text { Is it clear that the data justify the } \\
\text { conclusions drawn? }\end{array}$ \\
\hline Reproducibility & $\begin{array}{l}\text { Could the study be repeated by other } \\
\text { researchers? }\end{array}$ \\
\hline Prospective & Is the study prospective? \\
\hline Ethical issues & $\begin{array}{l}\text { Are all ethical issues articulated and } \\
\text { managed appropriately? }\end{array}$ \\
\hline Triangulation & $\begin{array}{l}\text { Were the results supported by data from } \\
\text { more than one source? }\end{array}$ \\
\hline
\end{tabular}

BEME, Best Evidence in Medical Education.

we will use the recent Synthesis Without Meta-analysis guidelines. $^{23}$

\section{DISCUSSION}

The findings of this review will inform educators and institutions around the world on the effectiveness of VR and AR devices for teaching medical students and on how they are being used. This will provide useful information for organising bodies and medical schools when designing future curricula and developing educational interventions.

The outcomes for educational practice include improving the delivery of digital education, and ensuring that investment in digital technologies, including VR and AR, for medical schools, is justified. Institutions will be better informed when exploring such devices, and will be able to ensure they are tailored to and have been tested for, the needs of their students

In future, this review could also be used to develop a set of outcome criteria for testing and deploying immersive technologies.

\section{ETHICS AND DISSEMINATION}

Ethical approval is not required for this systematic review as no primary data are being collected. We will disseminate the findings of this review at scientific conferences and through publication in a peer-reviewed journal.
Author affiliations

${ }^{1}$ School of Medicine, University of Dundee, Dundee, UK

${ }^{2}$ College of Medicine and Veterinary Medicine, The University of Edinburgh,

Edinburgh, UK

${ }^{3}$ School of Medical Sciences, The University of Manchester Faculty of Biology Medicine and Health, Manchester, UK

${ }^{4}$ Barking Havering and Redbridge University Hospitals NHS Trust, Romford, UK

${ }^{5}$ School of Computing, Edinburgh Napier University, Edinburgh, UK

${ }^{6}$ Darwin College, University of Cambridge, Cambridge, UK

${ }^{7}$ Usher Institute, University of Edinburgh, Edinburgh, UK

Twitter Zain Hussain @zhuss95, Debbie Aitken @debbieaitken and Aziz Sheikh @ drazizsheikh

Acknowledgements The authors would like to acknowledge Ruth Jenkins, Academic Support Librarian at the University of Edinburgh, for helping develop ofthe search strategy and identify relevant databases. They would also like to acknowledge the BEME Collaboration for their insightful feedback on their Topic and Protocol registration.

Contributors $\mathrm{ZH}$ and DMN contributed equally to this paper. ZH and DMN conceived and planned the review, with supervision from AS, DA and AH. ZH, DMN and NA wrote the initial draft, with critical intellectual contributions from all the coauthors (ZS, NN, AK, AH, DA, AS). All authors approved the final version.

Funding The authors have not declared a specific grant for this research from any funding agency in the public, commercial or not-for-profit sectors.

Competing interests None declared.

Patient consent for publication Not required.

Provenance and peer review Not commissioned; externally peer reviewed.

Supplemental material This content has been supplied by the author(s). It has not been vetted by BMJ Publishing Group Limited (BMJ) and may not have been peer-reviewed. Any opinions or recommendations discussed are solely those of the author(s) and are not endorsed by BMJ. BMJ disclaims all liability and responsibility arising from any reliance placed on the content. Where the content includes any translated material, BMJ does not warrant the accuracy and reliability of the translations (including but not limited to local regulations, clinical guidelines, terminology, drug names and drug dosages), and is not responsible for any error and/or omissions arising from translation and adaptation or otherwise.

Open access This is an open access article distributed in accordance with the Creative Commons Attribution Non Commercial (CC BY-NC 4.0) license, which permits others to distribute, remix, adapt, build upon this work non-commercially, and license their derivative works on different terms, provided the original work is properly cited, appropriate credit is given, any changes made indicated, and the use is non-commercial. See: http://creativecommons.org/licenses/by-nc/4.0/.

\section{ORCID iDs}

Zain Hussain http://orcid.org/0000-0002-0559-8289

Zakariya Sheikh http://orcid.org/0000-0003-4147-4205

Nathan Ng http://orcid.org/0000-0001-7063-6870

Amir Hussain http://orcid.org/0000-0002-8080-082X

Aziz Sheikh http://orcid.org/0000-0001-7022-3056

\section{REFERENCES}

1 Smith SR, Dollase R. AMEE guide No. 14: Outcome-based education: part 2-Planning, implementing and evaluating a competency-based curriculum. Med Teach 1999;21:15-22.

2 Benes V. The European working time directive and the effects on training of surgical specialists (doctors in training). Acta Neurochir 2006;148:1020-6.

3 Scott DJ, Bergen PC, Rege RV, et al. Laparoscopic training on bench models: better and more cost effective than operating room experience? J Am Coll Surg 2000;191:272-83.

4 Bridges M, Diamond DL. The financial impact of teaching surgical residents in the operating room. Am J Surg 1999;177:28-32.

5 Blumstein G, Zukotynski B, Cevallos N, et al. Randomized trial of a virtual reality tool to teach surgical technique for tibial shaft fracture intramedullary nailing. J Surg Educ 2020;77:969-77.

6 Nicholson DT, Chalk C, Funnell WRJ, et al. Can virtual reality improve anatomy education? a randomised controlled study of a computer- 
generated three-dimensional anatomical ear model. Med Educ 2006;40:1081-7.

7 Moran J, Briscoe G, Peglow S. Current technology in advancing medical education: perspectives for learning and providing care. Acad Psychiatry 2018;42:796-9.

8 Aïm F, Lonjon G, Hannouche D, et al. Effectiveness of virtual reality training in orthopaedic surgery. Arthroscopy 2016;32:224-32.

9 Moro C, Štromberga Z, Raikos A, et al. The effectiveness of virtual and augmented reality in health sciences and medical anatomy. Anat Sci Educ 2017;10:549-59.

10 Mantovani F, Castelnuovo G, Gaggioli A, et al. Virtual reality training for health-care professionals. Cyberpsychol Behav 2003;6:389-95.

11 Childs S, Blenkinsopp E, Hall A, et al. Effective e-learning for health professionals and students--barriers and their solutions. A systematic review of the literature--findings from the HeXL project. Health Info Libr J 2005;22 Suppl 2:20-32.

12 Nagendran M, Gurusamy KS, Aggarwal R, et al. Virtual reality training for surgical trainees in laparoscopic surgery. Cochrane Database Syst Rev 2013;193.

13 Sikder S, Tuwairqi K, Al-Kahtani E, et al. Surgical simulators in cataract surgery training. Br J Ophthalmol 2014;98:154-8.

14 Piromchai P, Avery A, Laopaiboon M, et al. Virtual reality training for improving the skills needed for performing surgery of the ear, nose or throat. Cochrane Database Syst Rev 2015;112.

15 Kyaw BM, Saxena N, Posadzki P, et al. Virtual reality for health professions education: systematic review and meta-analysis by the digital health education collaboration. J Med Internet Res 2019;21:e12959.

16 Halfer D, Rosenheck M. Virtual education: is it effective for preparing nurses for a hospital move? J Nurs Adm 2014;44:535-40.

17 Semeraro F, Ristagno G, Giulini G, et al. Virtual reality cardiopulmonary resuscitation (CPR): comparison with a standard CPR training mannequin. Resuscitation 2019;135:234-5.

18 Wright D, Harvey K, McQueen E. SC22 teaching emergency assessment to medical students (teams): introducing medical students to an ABC approach using virtual reality. BMJ 2019:2-32.
19 Dardick J, Allen S, Scoco A, et al. Virtual reality simulation of neuroendovascular intervention improves procedure speed in a cohort of trainees. Surg Neurol Int 2019;10:184.

20 Ebert J, Tutschek B. Virtual reality objects improve learning efficiency and retention of diagnostic ability in fetal ultrasound. Ultrasound Obstet Gynecol 2019;53:525-8.

21 Taubert M, Webber L, Hamilton T, et al. Virtual reality videos used in undergraduate palliative and oncology medical teaching: results of a pilot study. BMJ Support Palliat Care 2019;9:281-5.

22 Tang KS, Cheng DL, Mi E, et al. Augmented reality in medical education: a systematic review. Can Med Educ J 2020;11:e81-96.

23 Campbell M, McKenzie JE, Sowden A, et al. Synthesis without meta-analysis (swim) in systematic reviews: reporting guideline. BMJ 2020;368:16890.

24 Hoffman H, Vu D. Virtual reality. Academic Medicine 1997;72:1076-81.

25 Cohen J. A coefficient of agreement for nominal scales, 2007. Available: http://epm.sagepub.comhttp//epm.sagepub.comhttp:// www.sagepublications.comhttp://epm.sagepub.com/cgi/ alertsEmailAlerts:http://epm.sagepub.comhttp://www.sagepub.com/ http://epm.sagepub.com [Accessed 16 Oct 2020].

26 Ouzzani M, Hammady H, Fedorowicz Z, et al. Rayyan-a web and mobile APP for systematic reviews. Syst Rev 2016;5:1-10.

27 Shamseer L, Moher D, Clarke M, et al. Preferred reporting items for systematic review and meta-analysis protocols (PRISMA-P) 2015: elaboration and explanation. BMJ 2015;349:g7647.

28 Higgins JPT, Green S. Cochrane Handbook for systematic reviews of interventions version 5.1.0, 2011. Available: www.cochranehandbook.org

29 Buckley S, Coleman J, Davison I, et al. The educational effects of portfolios on undergraduate student learning: a best evidence medical education (BEME) systematic review. BEME guide No. 11. Med Teach 2009;31:282-98.

30 Kirkpatrick DL, Kirkpatrick JD. Evaluating training programs: the four levels. 3rd ed. San Francisco, CA: Berrett-Koehler, 2006. 